\title{
JORNADES D'ESCOLA I CINEMA: RELAT DESCRIPTIU DE LES \\ DUES EDICIONS ORGANITZADES PER A LA FORMACIÓ DELS \\ DOCENTS A LA UNIVERSITAT D'ALACANT
}

\author{
Antonio GINER GOMIS \\ Francisco R. PASTOR VERDÚ \\ Facultat d'Educació \\ Universitat d'Alacant
}

Per als que ens dediquem a la tasca docent des de la formació inicial en les escoles de Magisteri, hi ha una qüestió que ens afecta i que resulta especialment pertinent en la introducció a aquest projecte. Ens referim al fet de pensar i posar en pràctica aquelles formes o maneres d'organitzar el coneixement que volem ensenyar.

Des d'aquest interès i amb la pretensió de reflexionar sobre l'ofici de mestre dins d'aquella formació universitària que precisament permet obtenir aquesta titulació a través de diferents especialitats, aquest treball vol contribuir, si això és possible, a un enriquiment de la mirada professional de qui tindrà en un futur pròxim la possibilitat de fer créixer vitalment, intel-lectualment o emocionalment en les aules aquelles generacions de joves, ciutadans d'aquest país.

Hi ha un interès explícit i generalitzat en les escoles de magisteri en l'abordatge durant aquest període de formació inicial i des de diversos angles possibles -conceptual, procedimental o actitudinal- de la professió docent. Un tractament global de l'experiència profesionalitzadora que pretendria un perfil humà on es guanyara en profunditat i comprensió epistemològica, desenvolupament ètic, amplitud d'horitzons vitals, enriquiment professional... En definitiva, elaboració d'una mirada especial, la mirada del mestre.

Tradicionalment, la teoria i la pràctica han sigut les dues vies per excel-lència a través de les quals s'han anat construint aquells marcs interpretatius i d'actuació que ens han possibilitat la construcció d'un coneixement professional. En la direcció d'entrellaçar ambdós, com un aspecte bàsic en l'organització d'aquesta experiència d'aprenentatge dirigida a l'alumnat de l'escola de Magisteri d'Alacant, en la tessitura de fer didàctics aquells recursos que tenim més a mà i sent conscients de les potencialitats 
inherents que comporta la cultura mediàtica en què estem immersos s'ha anat gestant aquest treball.

El resultat de tot això ha suposat considerar una trobada entre el cine i els mestres com a pretext per a pensar sobre aquest ofici mitjançant aquestes jornades.

Què ens aporta el cine sobre aquesta professió?

Des del nostre punt de vista, i tal com l'interpretem, el cine, com a mitjà, no deixa de ser una mirada subjectiva a la vida, una mirada acolorida, mediatitzada per la sensibilitat del qui observa, mira o contempla la realitat i tracta de capturar-la una altra vegada a través de la càmera. De fet, el format cinematogràfic ens ofereix o reflecteix diverses imatges sobre la professió docent que ens ha semblant interessant portar ací a la vostra consideració.

\section{Edició de les jornades d'Escola i Cinema}

En aquest primer cicle de pel-lícules durant el curs acadèmic 2006, les temàtiques van plantejar dos possibles matisos sobre els quals centrar un potencial debat posterior:

a. El significat de ser mestre o mestra.

b. El significat de la paraula ensenyar.

Estem convençuts que aquests interrogants transcendeixen la diversitat de cultures en el sentit que no són ni unívocs ni inequívocs i que els seus possibles significats ens poden ajudar a comprendre millor la nostra professió en aquests temps d'incerteses; alhora, som conscients també que aquest format cinematogràfic reflecteix parcialment aquesta professió en la mesura que hi ha moltes altres imatges d'aquest ofici des de diferents àmbits socials (literatura, anuncis publicitaris, etc.).

\section{4 pressupòsits teòrics que justifiquen aquestes jornades}

En tractar d'emmarcar aquest primer cicle d' Escola $i$ Cinema, es fa necessari justificar-ne la presentació a partir de quatre enfocaments amb els quals considerar-lo: el 
punt de vista pròpiament cinematogràfic, el punt de vista narratiu, el metafòric i el de la diversitat cultural.

\section{El punt de vista cinematogràfic}

Amb ell volem referir la pertinença de la selecció d'aquest mitjà de transmissió cultural massiva, de comunicació a grans audiències, com ideal per a utilitzar-lo, en aquest cas, també, en grups d'alumnes aprenents de mestres i com a pretext visual per a reflexionar sobre aquesta professió.

Pensem, en aquest sentit, que és molt raonable per als nostres interessos tirar mà d'aquells recursos que la cultura audiovisual en què estem immersos ens ofereix.

D'altra manera, el format fílmic ens ofereix la possibilitat de fer-los servir com a materials idonis que ens permeten analitzar, interpretar i deliberar sobre aquells aspectes didàctics de l'univers visual en què estem immersos, d'aquest món replet d'imatges i del que no podem sostraure'ns com a educadors si volem ser conscients del nostre quefer didàctic.

\section{El punt de vista narratiu}

Per altra part, quina mirada ens ofereixen els directors cinematogràfics sobre l'ensenyament i sobre els que la realitzen?

Què se'ns queda en la retina després de veure les diverses i particular visions de la professió docent que ens ofereixen aquests realitzadors?

Aquestes i altres qüestions que puguen emergir en el cicle es constitueixen com a línies directrius que marquen els interessos del nostre projecte.

De la mateixa manera ens ha semblant pertinent abordar l'estudi de la professió docent a través del cinema, ja que és un mitjà on predomina l'aspecte narratiu del discurs que es vol transmetre. En efecte, és aquesta una modalitat particular de tractament d'un tipus de coneixement que, segons ho expressa Bruner (1997), permet als éssers humans gestionar el coneixement que ha de veure amb la gent i les seues situacions; o, com afirma Carbonell (2006), seguint el mateix prestigiós psicòleg nordamericà, és la manera en què donem compte de la identitat sobre nosaltres mateixos i sobre el món. 
El tipus narratiu es configura com un format adequat als nostres interessos, ja que hi podem albirar millor, com també afirma Jackson (1986), les virtuts, els traços de caràcter, els interessos, les actituds, els valors i en definitiva tots aquells components de l'àmbit moral que impregnen irremeiablement l'acte educatiu.

I dins d'aquest format narratiu, on situem el relat dialogat, -usual en el format cinematogràfic- no hi ha dubte, és un dels mitjans més poderosos de què es disposa per a comunicar la nostra visió de l'experiència humana.

Així doncs, la narrativitat, en aquest cas adoptant el matís de diàleg interpersonal, es constitueix com una variable especialment interessant en la selecció del material cinematogràfic com a particularment idoni per a aproximar-nos als interessos del nostre projecte.

\section{El punt de vista metafòric}

La narració cinematogràfica pot implicar de la mateixa manera un aspecte metafòric en la mesura que puga suggerir significats que vagen més enllà de l'aparentment explícit.

Metaforitzar la professió és dotar-la de potencials significats que ens permeten orientar la nostra actuació en un sentit o en un altre.

Estem convençuts que en el procés de comprendre quins significats pot implicar l'ensenyament o quins significats genera la paraula mestre o mestra, pot ser interessant convertir o transformar aquells termes en imatges metafòriques amb les quals puguem donar una forma comprensible, corpòria, amb formes, sons i sensacions a aquells termes per a fer-los nostres, per a viure'ls com a propis en un intent de comprendre'ls millor. Metaforitzar aquesta professió ens pareix un recurs valuós al mateix temps que ens resulta provisional, perquè no sols es tracta de facilitar la comprensió de determinats conceptes -ensenyament i mestre- o la posada en pràctica de determinats enfocaments històrics sobre aquests mateixos conceptes, sinó, i també, de saber que sent aquestes metàfores una construcció social, puguem, sent-ne conscients, utilitzar-les per a explorar i aprofundir en el nostre ofici tant com per a allunyar-nos-en substituint-les per unes altres de més potents, aclaridores, transformadores que ens permeten anar un poc més enllà en el nostre procés de transformació personal com a mestres. 
Pretenem a través de la diversitat de propostes cinematogràfiques que ens ofereix aquest cicle, contribuir a un enriquiment metafòric personal com a recurs per a explorar l'ofici de mestre.

\section{El punt de vista de la diversitat cultural}

Un últim interès explícit en el nostre projecte ha sigut el de considerar la riquesa afegida al discurs sobre la docència que s'origina quan les pel-lícules d'aquesta primera edició provenen de diferents àmbits culturals.

Com es contempla l'ensenyament i la diversitat de problemàtiques associades a ella des de diferents contextos geogràfics, físics i socials, en definitiva culturals, és un altre dels criteris amb què hem seleccionat els films d'aquest cicle.

Plantejar la professió docent des de la diversitat cultural pretén obrir possibilitats a la comprensió i consideració no sols de diferents sistemes educatius, sinó, i també, de les relacions educatives que mestres, alumnes o famílies s'estableixen dins d'aquestes institucions, així com de les particulars relacions dialògiques que l'escola pretén dins de la societat on es troba immersa o d'aquelles altres que assumeix sent-ne conscient o no.

Busquem, en definitiva, una visió comprensiva del fenomen educatiu emfatitzant les qüestions que plantegen la polisèmia dels termes ensenyament, mestre o mestra; una comprensió que ens resulta imprescindible si, com afirma Thich Nhat Hanh, candidat al premi Nobel de la Pau, volem estimar qualsevol cosa.

En aquest cicle, hem substituït "qualsevol cosa" per la paraula mestre o mestra. Ara falta saber si, quan acabe, s'haurà aconseguit alguna cosa en aquest sentit.

\section{Jornades d'Escola i Cinema}

La convocatòria de les II Jornades de Cinema i Educació en el curs acadèmic 2007 es va fer des de l'empeny de configurar un context on poder compartir durant cinc dies una selecció de produccions cinematogràfiques que tenien com a característica particular la seua estreta relació amb el món de l'educació.

En aquesta ocasió, el fil conductor es va confegir sobre cinc diferents narracions filmiques que tractaren de suggerir cinc diferents camins o didàctiques específiques per desenvolupar a l'alumnat d'una manera integral. Aquestes visions particulars sobre com 
ensenyar i aprendre des de l'especifitat disciplinar aportades per la filmografia triada, s'ha complementat amb les dels mestres ponents, totes elles farcides de les xicotetes anècdotes quotidianes que dia rera dia acaben per construir una manera d'interpretar la realitat educativa i de com intervenir-hi. Curiosament, després d'escoltar les veus d'aquests professionals, la diversificació que es proposa en aquestes jornades respecte de com ensenyar en àrees disciplinars diferents, no condueix com es podria pensar a l'aparició de distintes didàctiques, sinó més bé a la conveniència de compartir un conjunt d'estratègies d'ensenyament comunes que tan pertinents semblen per a la construcció de coneixements matemàtics, com lingüístics, com socioculturals... Obviament la realitat no es troba compartimentada en parcel·les de coneixement, sinó que es conforma sobre una globalitat que interelaciona distintes facetes de la vida en una profunda simbiosi que, moltes vegades, és difícil de subdividir en elements simples.

Cadascuna de les pel-lícules era un punt de partida per tractar de percebre des de la butaca la complexitat de la vida i la complexitat del fet d'ensenyar, i com entre aquests dos es situen les persones amb tot el seu equipatge de destijos, interessos, actituds, sentiments, la qual cosa permetia descobrir que aprendre i ensenyar a interpretar aquest món des de la diversitat de les mirades no és una tasca gens senzilla, ni molt menys.

Amb la primera de les projeccions, Padre Padrone, la mirada de l'espectador podia prendre diferents direccions, però si és cert que amb el posterior col·loqui i intervencions del ponent, la qüestió sociològica i la importància de l'educació del ser en societat, del desenvolupament de la persona i el seu alliberament gràcies als altres a través d'un procés educatiu, foren els pensaments més fortament compartits.

Des del visionament de la pel-lícula El indomable Will Hunting, es suscità un posicionament crític devers els plantejaments educatius que tradicionalment s'hi fa a les aules respecte de les matemàtiques, i com aquells, com diu Bishop (1999) haurien de repensar-se per poder desenvolupar els vertaders valors que cadascuna de les cultures d'aquest planeta va cercar amb la seua construcció cultural: ajudar a interpretar aquest món i poder transformar-lo. Les matemàtiques, per tant, haurien d'acostar-se a la vida quotidiana dels xiquets i aportar-li referents per poder entendre-la, cosa que es pogué constatar amb la presentació de diverses experiències pràctiques d'aula per part de la ponent.

Los chicos del coro obrí les portes a una evidència: la música, i juntament amb ella, totes les manifestacions artístiques humanes, són l'aliment espiritual innegable de 
la persona. La música recrea les emocions en el temps i les farceix de múltiples imatges que no són perceptibles en ella. I aquestes imatges s'activen en el temps des de l'escolta de les peces musicals que van quedar lligades, en un moment donat de la vida, fent que la persona viatge més enllà de la realitat física. El diàleg sorgit a partir de la pel-lícula i promogut pel ponent, va evidenciar l'enorme contradicció que viu l'escola, quan a penes deixa subsistir una educació musical autèntica a les aules, educació musical que fonamentalment facilitara camins per a aprendre a escoltar amb tots els sentits la diversitat musical i poder gojar-ne.

L'atenció a la diversitat en les aules integra en el seu si l'atenció de les necessitats educatives especials i és d'agrair que en els darrers anys aquesta educació estiga superant, amb grans entrebancs, les connotacions peioratives que al llarg dels anys ha acumulat, i front a la separació i el dèficit es rescata la integració i la valoració global de la persona. La pel-lícula El milagro de Ana Sullivan va ser el teló de fons d'un col-loqui que ressaltà, amb la presència i la paraula del mestre intervinent la necessitat d'educar als alumnes amb necessitats educatives especials des de la globalitat de la persona i on la pràctica psicomotriu relacional es converteix, en aquest sentit, en una estratègia altament positiva.

La cloenda d'aquest cicle de cinema i educació la van posar la projecció de $\mathrm{Ni}$ uno menos i la intervenció del mestre participant en aquesta jornada. Des de la mateixa projecció d'aquest film, vam poder participar en diferents activitats pràctiques que ens animaven a participar en propostes didàctiques integradores de la llengua i el cinema. El resultat ens permeté albirar que el cinema, com a mitjà de comunicació i expressió de sentiments amb un llenguatge propi, podria i deuria ser reivindicat a les aules per al seu tractament didàctic.

Per als que ens dediquem a la tasca docent -siga des de l'etapa d'infantil fins a la Universitat- hi ha una qüestió que ens afecta i que resulta especialment pertinent en la introducció del cinema com eina d'aprenentatge. Ens referim al fet o necessitat de pensar i posar en pràctica a les aules aquelles formes o maneres d'organitzar el coneixement que volem ensenyar.

En la tessitura de fer didàctics aquells recursos que tenim més a mà per crear aquelles situacions d'aprenentatge amb les que organitzar la transmissió cultural que comporta l'acte d'educar i sent conscients de les potencialitats inherents que comporta la cultura mediàtica en què estem immersos, es pot considerar una trobada molt interessant la que es produeix entre el cinema i l'escola. 
Què ens pot aportar el cine (acotat, en aquest moment a les ficcions narratives exhibides públicament) a la nostra professió docent?

Des del nostre punt de vista, i tal com l'interpretem, el cinema, com a mitjà de transmissió cultural, no deixa de ser una mirada subjectiva a la vida, una mirada acolorida, mediatitzada per la sensibilitat del qui observa, mira o contempla la realitat $\mathrm{i}$ tracta de capturar-la una altra vegada a través de la càmera; de tal manera que, a aquesta especificitat personal podem afegir la riquesa que s'origina quan les pel-lícules provenen de diferents àmbits culturals.

Pensem que el cinema pot ser un pretext idoni per a estimular la curiositat o promoure les ganes d'investigar i comprendre la realitat física, material, històrica, social que ens envolta o desenvolupar el record o l'argumentació i el posicionament ètic sobre pràcticament qualsevol tema que ens parega rellevant... Sempre i quan, evidentment, sapiguem aprofitar, en aquest cas didàcticament, aquestes narratives fílmiques en funció de les nostres intencionalitats educatives.

Nosaltres hem distingit tres aspectes cinematogràfics complementaris que proposem com una possible ajuda pels estudiants a l'hora de comentar una pel.lícula:

\section{Àmbit tècnic de la pel-lícula}

La factura tècnica de l'obra pot suggerir-nos algunes qüestions: la imatge, el so, els plans, la interpretació, el fil argumental, la resolució dels temps i les cadències de les històries que es presenten, etc., poden donar-nos algunes de les pistes que ens ajuden a presentar alguna qüestió que ens parega interessant argumentar, atès que tot aquest desplegament tècnic està contribuint $-\mathrm{i}$, per tant, no és gratuït- a donar forma a un contingut. Recordeu que l'embolcall, el contenidor, la forma també és contingut. És en aquest sentit que proposem o suggerim algunes qüestions:

Quins efectes relacionats amb el color, el so o les imatges, el temps narratiu et pareixen més cridaners i per què penses que ho són?

Quins recursos o figures narratives -com per exemple les metàfores- creus que s'utilitzen per a embastar la història que se'ns presenta?

El guió et sembla suggeridor, emotiu, fred? Per què? Què et pareix el ritme narratiu -accelerat, lent, tranquil, etc.- amb el que conten la història? Creus que aquest ritme influencia d'alguna manera el nostre viure quotidià? 
Àmbit de la contextualització temporal o espacial i dels personatges

La narració fílmica es troba, de manera indefugible, incardinada en un temps i un espai recreat en l'obra. Aquest context espacio-temporal pot ser també considerat com un element clau que ens ajuda a entendre i interpretar millor l'abast de la pel-lícula.

Creus que el context espacial i temporal -el paisatge- ajuda a definir i a recrear als personatges -el paisatge-?

La quotidianeïtat és reflectida encertadament o tal vegada és artificial? Hi ha distorsions cridaneres, detalls o errades que no encaixen en la trama?

Et suggereix alguna cosa la particular ambientació de la pel·lícula?

\section{Àmbit pedagògic i didàctic}

Aquest seria l'espai específic que tractaria de desencadenar certa reflexió i argumentació sobre les temàtiques específiques que puguerem reflectir-se en la pel-lícula en relació als nostres interessos didàctics particulars. En aquest sentit podríem preguntar-nos coses com:

Quina concepció o concepcions rellevants al nostre parer i al voltant de la nostra particular àrea curricular se'ns mostren en el film?

Com podríem definir-la o definir-les?

Quines diferències o similituds podríem trobar entre el que ens presenten en la pel-lícula i la de la nostra realitat local?

Quina valoració global et mereixeria la pel-lícula pel que fa al que pot aportar a les teues idees sobre el tema que puguem estar tractant?

En què et bases per a justificar la teua argumentació?, etc.

Però per a poder parlar sobre tot això hem d'esperar que el focus de la cabina deixe de projectar i s'encenguen les llums de la sala. Aconseguirà també el cine que s'encenguen les llums de la nostra ment? D'això es tracta. 
BIBLIOGRAFIA:

BISHOP, A., Enculturación matemática. La educación matemática desde una perspectiva cultural, Barcelona, Paidós, 1999.

BRUNER, J., La educación, puerta de la cultura, Madrid, Aprendizaje-Visor, 1997.

JACKSON, P. W., La vida en las aulas, Madrid, Marova, 1975.

CARBONELL, J. y TORT, A., La educación y su representación en los medios, Madrid, Morata, 2006. 